\title{
PERANAN PERPUSTAKAAN DALAM MENINGKATKAN LITERASI INFORMASI BAGI NARAPIDANA DI LEMBAGA PEMASYARAKATAN PEREMPUAN KLAS IIA TANGERANG
}

Billy Ainul Ilham

Taruna Politeknik Ilmu Pemasyarakatan

Email: billy.ainulilham22@gmail.com

\begin{abstract}
Abstrak:
Literasi informasi merupakan suatu modal sosial cukup penting bagi masyarakat millennial saat ini, karena dengan itu dapat mendorong kehidupan menjadi lebih baik. Setiap individu memiliki hak untuk mendapatkan dan juga memanfaatkan informasi, tak terkecuali bagi Narapidana. Akan tetapi, para narapidana mempunyai akses informasi yang masih terbatas saat berada di dalam Lapas serta tidak semua informasi juga mudah diperoleh oleh Narapidana. Berdasarkan persoalan tersebut, pembahasan mengenai peranan perpustakaan dalam meningkatkan literasi informasi bagi narapidana di Lembaga Pemasyarakatan Perempuan Klas IIA Tangerang cukup penting dilakukan untuk mengetahui peranan perpustakaan terhadap literasi informasi bagi narapidana. Tujuan penelitian ini ialah untuk dapat mengetahui sejauh mana peranan perpustakaan dalam meningkatkan literasi informasi bagi narapidana. Metode yang digunakan dalam penelitian ini menggunakan metode penelitian deskriptif melalui pendekatan kualitatif. Teknik pengumpulan data dilaksanakan dengan wawancara, observasi dan studi literatur. Alhasil dari penelitian ini menunjukkan bahwa Perpustakaan Lembaga Pemasyarakatan Perempuan Klas IIA Tangerang memiliki peranan sebagai sumber informasi, wadah untuk berkreasi dan menjadi tempat untuk kegiatan pembelajaran bagi para narapidana. Literasi informasi bagi narapidana di Lembaga Pemasyarakatan Perempuan Klas IIA Tangerang mempunyai fasilitas yang cukup baik, koleksi-koleksi yang dimiliki perpustakaan cukup bervariatif seperti pengetahuan umum, legenda, keagamaan, majalah serta buku keterampilan. Peranan perpustakaan dalam meningkatkan literasi informasi bagi para narapidana dapat dilihat melalui karya- karya yang dihasilkan oleh para narapidana, seperti halnya berupa karya seni rupa, buku yang menceritakan tentang kehidupan sehari-hari narapidana di dalam lembaga pemasyarakatan serta budidaya tanaman yang dilakukan para narapidana.
\end{abstract}

Kata kunci: Perpustakaan, Lembaga Pemasyarakatan, Literasi Informasi, Narapidana.

Abstract:

Information literacy is an important social capital for the millennial community today, because it can encourage a better life. Every individual has the right to obtain and also use information, including Prisoners. However, prisoners have limited access to information while in prison and not all information is easily obtained by prisoners. Based on these problems, the discussion about the role of libraries in increasing information literacy for inmates at the Tangerang Class IIA Women's Penitentiary is quite important to know about the role of libraries in information literacy for prisoners. The purpose of this study is to be able to know the extent of the role of libraries in improving information literacy for inmates. The method used in this study uses descriptive research methods through a qualitative approach. Data collection techniques carried out by interview, observation and study of literature. As a result of this study shows that the Tangerang Class IIA Women's Penitentiary Library has a role as a source of information, a place to be creative and a place for learning activities for prisoners. Information literacy for inmates at the Tangerang Class IIA Women's Penitentiary has quite good facilities, collections owned by the library are quite varied such as general knowledge, legends, religion, magazines and skill books. The role of libraries in increasing information literacy for prisoners can be seen through works produced by inmates, such as art works, books that tell about prisoners' daily lives in prison and plant cultivation by prisoners.

Keyword: Prison Library, Correctional Institution, Information of literacy, Inmates . 
Billy Ainul Ilham

Peranan Perpustakaan Dalam Meningkatkan Literasi Informasi

\section{PENDAHULUAN}

Lembaga pemasyarakatan adalah tempat untuk melaksanakan pembinaan narapidana dan anak didik pemasyarakatan1. Seorang Narapidana me-njadi orang yang sedang diasingkan karena dam-pak negatif atas perbuatannya. Walaupun de-mikian, seorang narapidana tetap memiliki hak dalam memperoleh bahan bacaan, serta menga-kses terhadap mediamedia lainnya sebagai su-mber informasi. Lembaga Pemasyarakatan menjadi wadah bagi narapidana dalam menciptakan budaya lokal sendiri yang dilakukan secara tur-un-temurun. Budaya lokal tersebut salah satu-nya adalah pemanfaatan perpustakaan dan kegiatan literasi oleh narapidana. Lingkungan narapidana yang bersifat heterogen menjadi tan-tangan tersendiri bagi perpustakaan dalam mem-berikan layanan informasi,seperti bahan pustaka kepada narapidana. Informasi yang dapat di ma-nfaatkan narapidana masihterbatas sehingga hanya informasi dengan konten tertentu yang dapat diakses narapidana.

Perpustakaan yang terdapat pada Lem-baga Pemasyarakatan (lapas) merupakan perpu-stakaan khusus sehingga pengguna pelayanan pun bersifat khusus, yakni para narapidana saja. Maka, hal ini menyebabkan narapidana memiliki akses informasi terbatas. Perpustakaan khusus didefinisikan sebagai suatu organisasi informasi yang disponsori oleh suatu instansi atau perusa-haan, baik swasta maupun pemerintah yang ber-tugas mengumpulkan, menyimpan, dan men-yebarkan informasi dengan menekankan koleksi-nya pada suatu bidang tertentu dan bidangbidang yang berhubungan dengan bidang terse-but serta untuk pemakai tertentu pula. 2

Perpustakaan khusus umumnya juga memiliki subyek yang ditangani, koleksi yang dikelola, pemakai yang dilayani serta kedudukannya. Kedudukan

${ }^{1}$ Undang-undang No. 12 Tahun 1995 tentang Pemasyarakatan ${ }^{2}$ Kamariah Tambunan,"kajian perpustakaan khusus dan sumber informasi di indonesia", Jurnal dokumentasi dan informasi vol. 34 no. 1, 2013, hal. 31. atau status dapat berarti di bawah naungan suatu lembaga, badan atau org-anisasi; tenaga yang mengelola memiliki kema-mpuan spesifik yang terkait dengan bidang sub-jek perpustakaan; koleksi yang dimiliki dan dila-yankan terbatas pada subyek yang menjadi mi-nat tertentu dari pemustaka atau penggunanya; dan pengguna yang berasal dari komunitas atau kalangan tertentu yang mempunyai minat ter-tentu pula.

Perpustakaan Lembaga pemasyarakatan merupakan perpustakaan khusus dalam ruang lingkup lokal mempunyai keunikan dalam mem-bangun suatu budaya literasi informasi. Perpus-takaan ini memiliki nilai kebiasaan yang terba-ngun secara alamiah serta dilakukan secara tu-run-temurun di dalam lingkup lapas untuk bera-daptasi dengan lingkungan.

Sesuai rujukan ini, peningkatan literasi informasi dapat dilakukan narapidana di Lemba-ga Pemasyarakatan (Lapas). Narapidana merup-akan masyarakat yang mempunyai hakuntuk mendapatkan informasi. Namun, para narapida-na di dalam Lembaga Pemasyarakatan Perempuan Klas IIA Tangerang masih memiliki keterba-tasan akses dalam memperoleh informasi yang masih dibatasi oleh pihak Lembaga Pemasyara-katan (Lapas). Hal ini memiliki tujuan agar infor-masi yang didapat oleh narapidana tidak disalah-gunakan untuk kepentingan yang dapat merugi-kan narapidana di Lembaga Pemasyarakatan Perempuan Klas IIA Tangerang.

Perpustakaan Lembaga Pemasyarakatan Perempuan Klas IIA Tangerang hanya memfasili-tasi untuk para narapidananya melalui penye-diaan seperti halnya informasi tentang agama, hukum, bahasa, novel, komik, ilmu pengetahu-an, keterampilan dan beberapa bahan bacaan la-innya,pihak Lembaga pemasyarakatan juga memfasilitasi narapidana dalam melakukan kegiatan positif untuk meningkatkan kemampuan literasi, seperti menjalin kerja sama dengan 
kelompok belajar atau komunitas membaca. Narapidana di Lapas dapat memanfaatkan fasilitas perpustakaan seadanya saja. Walaupun demikian, hal ini telah melahirkan kearifan lokal ataupun budaya yang ada di dalam lingkungan Lembaga Pemasy-arakatan Perempuan Klas IIA Tangerang.

Berdasarkan latar belakang masalah di atas, penelitian ini penting dilakukan dengan tu-juan untuk mengetahui:

1. Apa peran Perpustakaan di Lapas dalam meningkatkan literasi inform-asi para narapidana?

2. Apa saja informasi yang di daphat oleh narapidana di Perpustakaan Le-mbaga Pemasyarakatan dalam men-ingkatkan literasi informasi?

3. Budaya lokal apa yang diciptakan Narapidana dalam kegiatan literasi di Perpustakaan Lembaga Pemasya-rakatan?

\section{METODE}

Desain penelitian yang digunakan adalah desain kualitatif deskriptif. Menurut Bogdan dan Taylor dalam Moleong, penelitian kualitatif sebagai prosedur penelitian yang menghasilkan data deskriptif berupa kata-kata tertulis atau lisan dari orang-orang dan perilaku yang dapat diamati . ${ }^{3}$ Senada dengan definisi tersebut Kirk dan Miller dalam Moleong mendefinisikan juga penelitian kualitatif adalah tradisi tertentu dalam ilmu pengetahuan sosial yang secara fundamental bergantung dari pengamatan pada manusia baik dalam kawasannya maupun dalam peristilahnya. Berdasarkan dua pengertian di atas, dapat disimpulkan bahwa penelitian kualitatif adalah penelitian yang bermaksud untuk memahami subjek yang akan diteliti, misal perilaku, persepsi, motivasi, dan tindakan dalam bentuk kata-kata dan bahasa dengan memanfaatkan berbagai metode.
Adapun pendekatan yang digunakan dalam penelitian ini adalah pendekatan deskriptif. Menurut Arikunto, pendekatan ini hanya menggambarkan "apa adanya" tentang suatu variabel, gejala atau keadaan. Pendekatan deskriptif mencoba mencari deskripsi yang tepat dan cukup dari semua aktivitas, objek, proses, dan manusia ${ }^{4}$ Dalam pendekatan deskriptif kualitatif data yang dikumpulkan adalah berupa katakata dan gambar bukan angka-angka.

\section{PEMBAHASAN}

Perpustakaan khusus adalah, perpustakaan yang diperuntukan secara terbatas bagi pemustaka di lingkungan lembaga pemerintah, lembaga masyarakat, lembaga pendidikan keagam-aan dan ru-mah ibadah atau organisasi lainnya ${ }^{5}$

Perpustakaan khusus memiliki ciri di antaranya koleksi perpustakaan lebih diutamakan un-tuk memenuhi kebutuhan organisasi induk, perp-ustakaan berada di bawah suatu organisasi induk, pengguna perpustakaan yang dilayani terbatas di lingkungan organisasi induk dan anggota asosiasi yang berada di organisasi tersebut. Per-pustakaan Lembaga pemasyarakatan berada di bawah organisasi Lembaga Pemasyarakatan, dan subjek koleksi perpustakaan mencakup koleksi yang bermanfaat untuk menambah wawasan dan menghibur bagi para narapidana.

Perpustakaan tersebut juga merupakan sa-lah satu sarana untuk mewujudkan keinginan dan harapan warga binaan dalam meraih cita-cita. Warga binaan, yakni narapidana tetap dapat belajar dan mengasah keterampilan sebagai be-kal ketika terbebas dari Lembaga Pemasyara-katan (LAPAS) dan terjun ke masyarakat melalui perpustakaan. Ketika warga bi-

${ }^{3}$ Lexi J. Moleong. 2010. Metodologi Penelitian Kualitatif. Bandung: PT. Remaja Roskakarya

${ }^{4}$ Suharsimi Arikunto.2013. Manajemen Penelitian. Jakarta: PT. Asdi Mahasatya

${ }^{5}$ Undang-undang No. 43 Tahun 2007 tentang Perpustakaan 
Billy Ainul Ilham

Peranan Perpustakaan Dalam Meningkatkan Literasi Informasi

naan berada di masyarakat, mereka akan menjadi sosok yang lebih baik dan bermanfaat. ${ }^{6}$

Sehubungan dalam meningkatkan Literasi pada narapidana agar menjadi pribadi yang lebih baik, hal ini juga dapat dikaitkan dengan 10 Prin-sip Pemasyarakatan, yang dimana ada pada poin pertama, dan berikut 10 prinsip pemasyarakatan yang dimaksud :

1. Ayomi dan berikan bekal hidup ag-ar mereka dapat menjalankan per-anannya sebagai warga masyarak-at yang baik dan berguna.

2. Penjatuhan pidana bukan tindakan ba-las dendam negara.

3. Berikan bimbingan bukan penyiksaan supaya mereka bertobat.

4. Negara tidak berhak membuat mereka menjadi lebih buruk atau jahat daripa-da sebelum dijatuhi pidana.

5. Selama kehilangan kemerdekaan bergerak, para narapidana dan anak didik harus dikenalkan dengan dan tidak bo-leh diasingkan dari masyarakat.

6. Pekerjaan yang diberikan kepada narapidana dan anak didik tidak boleh dibe-rikan pekerjaan untuk memenuhi keb-utuhan dinas atau kepentingan negara sewaktu-waktu saja. Pekerjaan yang diberikan harus satu dengan pekerjaan di masyarakat dan yang menunjang usaha peningkatan produksi.

7. Bimbingan dan didikan yang diberikan kepada narapidana dan anak didik har-us berdasarkan Pancasila.

8. Narapidana dan anak didik sebagai orang-orang yang tersesat adalah ma-nusia, dan mereka harus diperlakukan sebagai manusia.

9. Narapidana dan anak didik hanya dijat-uhi pidana hilang kemerdekaan sebagai salah satu derita yang dialaminya.

10. Disediakan dan dipupuk sarana-sarana yang dapat mendukung fungsi rehabili-tatif, korektif dan edukatif dalam Sis-tem Pemasyarakatan. ${ }^{7}$

Hanya dengan membaca para narapidana mene-rima informasi, memperdalam pengetahuan dan meningkatkan kecerdasan. Dalam proses belajar buku sebagai alat pembelajaran sangat penting. Eksistensi sebuah perpustakaan merupakan sua-tu hal yang wa-

${ }^{6}$ Karina Okta Bella,’Peran Perpustakaan Lembaga Pemasyarakatan Klas I Malang dalam meningkatkan literasi informasi narapidana", Jurnal kajian informasi \& perpustakaan vol. 7 no. 1, 2019, hal. 53

${ }^{7}$ Muhammad Kayyis Ar, "Mengenal 10 Prinsip Pemasyarakatan dalam Kegiatan Pembinaan Narapidana" (https://jarrak.id/catatan-redaksi-mengenal-10-prinsippemasyarakatan-dalam-kegiatan-pembinaan-narapidana/, Diakses pada 17 januari 2020, pukul 15.31) jib ada dalam sebuah lembaga, seperti halnya di Lembaga Pemasyarakatan Perempuan Klas IIA Tangerang. Perpustakaan meru-pakan gudangnya ilmu dan informasi bacaan, ba-ik yang berkaitan dengan dunia pendidikan mau-pun pengetahuan umum sehingga keberadaan perpustakaan di lingkungan lapas diharapkan da-pat memudahkan narapidana dalam mencari ilmu atau bahan bacaan lainnya, dengan demiki-an narapidana dapat mengembangkan wacana serta wawasannya lebih luas lagi. Lebih lanjut dapat dikatakan bahwa perpustakaan mempunyai peranan sangat penting dalam meningkatkan literasi informasi bagi narapidana di Lembaga Pemasyarakatan Perempuan Klas IIA Tangerang.

Informasi yang di dapat oleh narapidana di Perpustakaan Lembaga Pemasyarakatan Perempuan Klas IIA Tangerang.

Perpustakaan Lembaga Pemasyarakatan Perempuan Klas IIA Tangerang telah memfasilitasi kegiatan membaca dan memiliki kegiatan dalam memberikan pengetahuan serta meningkatkan kemampuan narapidana dalam mencari, meman-faatkan, serta menentukan kebutuhan informasi ke arah yang lebih positif. Berdasarkan kegiatan tersebut, para narapidana dapat meningkatkan keterampilan serta memperoleh hak yang sama meskipun masih berada di dalam lapas. Perpustakaan tersebut juga merupakan salah satu sara-na untuk mewujudkan keinginan dan harapan warga binaan dalam meraih cita-cita. Warga binaan, yakni narapidana tetap dapat belajar dan mengasah keterampilan sebagai bekal ketika ter-bebas dari Lembaga Pemasyarakatan Perempuan Klas IIA Tangerang dan siap terjun ke masyara-kat melalui pembelajara di perpustakaan. Ketika warga binaan berada di masyarakat, mereka akan menjadi sosok yang lebih baik dan berman-faat. Selain itu, Perpustakaan Lembaga pema-syarakatan dapat digunakan sebagai wadah bagi narapidana yang putus sekolah 
karena terjerat kasus pidana. Mereka mencari informasi menge-nai bahan belajar yang dibutuhkan untuk mengi-kuti kegiatan sekolah di dalam Lembaga Pemas-yarakatan.

Perpustakaan di Lembaga Pemasyarakatan Perempuan Klas IIA Tangerang tentunya berusa-ha menyediaan koleksi perpustakaan yang bersi-fat "memberi tahu" akan hal-hal yang berhubu-ngan dengan kepentingan para narapidana. Mel-alui membaca berbagai media bahan bacaan yang disediakan oleh perpustakaan lapas, para narapidana akan banyak tahu tentang segala hal yang terjadi pada saat ini. Para narapidana tidak cukup dengan hanya mendengarkan radio atau menonton televisi jika ingin mengetahui isu-isu yang terjadi. disekan oleh perpustakaan sekolah. Bagaimanapun juga dalam hal-hal tertentu bahan bacaan termasuk buku lebih mempunyai keu-nggulan relatif dibandingkan dengan media audio visual seperti televise yang ada di lapas. Disamp-ing itu buku dan bacaan lebih fleksibel bentuknya sehingga mudah di bawa oleh narapidana, buku juga mampu menjelaskan dan memberi petunjuk secara lebih praktis dan mendetil. Tambahan la-gi, melalui membaca, narapidana bisa menem-bus batas-batas ruang dan waktu, artinya walau raga mereka tidak bebas bergerak, tapi dengan membaca buku mereka akan tetap terbuka cak-rawalanya. Untuk informasi yang bisa di dapatkan oleh narapidana melalui perpustakaan cukup kompleks, dari buku-buku pengetahuan umum, sejarah, majalah, komik, keagamaan bahkan bu-ku-buku yang memberikan edukasi tentang kete-rampilan. Tentunya ini menjadi suatu pendorong bagi para narapidana di Lembaga Pemasyarkatan Perempuan Klas IIA Tangerang untuk menjadi pribadi yang lebih baik dan siap memiliki bekal untuk dapat kembali lagi ke masyarakat diluar sana.

Budaya lokal yang dalam kegiatan literasi di Perpustakaan Lembaga Pemasyarakatan Perempuan Klas IIA Tangerang
Perpustakaan Lembaga pemasyarakatan tidak memiliki pustakawan yang memiliki latar belakang pendidikan ilmu perpustakaan sehingga perpustakaan dikelola Bagian Pengelolaan Pembi-naan dan Kepribadian Lembaga Pemasyarakatan Perempuan Klas IIA Tangerang. Namun, jumlah petugas Lembaga Pemasyarakatan (Lapas) mas-ih terbatas untuk dialihkan sebagai pustakawan sehingga mereka merekrut narapidana untuk da-pat membantu mengelola perpustakaan Lemba-ga Pemasyarakatan (Lapas). Maka, narapidana yang bersedia membantu perpustakaan pun me-njadi pengelola perpustakaan.

Perekrutan narapidana menjadi pustakawan berpengaruh terhadap strata sosial narapidana tersebut di lingkungan Lembaga Pemasyarakatan (Lapas). Narapidana yang bertugas sebagai pustakawan akan lebih terhormat daripada narapidana yang tidak direkrut karena mereka akan mendapatkan perlakuan khusus, seperti ke-tika narapidana lain masuk sel, pustakawan bisa sedikit lebih bebas untuk melakukan aktivitas bekerja di perpustakaan dan di luar sel tahanan. Sesuai temuan data di atas, di Perpustakaan Lembaga Pemasyarakatan Perempuan Klas IIA Tangerang memiliki kearifan lokal yang tidak terda-pat di perpustakaan di luar lapas. Pustakawan di perpustakaan luar lapas pada umumnya diang-gap sebagai profesi yang jarang diminati masya-rakat sedangkan untuk pustakawan pada perpus-takaan Lembaga Pemasyarakatan (Lapas) meru-pakan profesi istimewa. Dimana narapidana ya-ng mampu menjadi pustakawan merupakan keh-ormatan tersendiri atau menjadi narapidana ter-hormat di antara narapidana yang lain. Selain mereka dihormati dalam lingkungan lapas, nara-pidana juga mendapatkan remisi karena dianggap sudah melakukan hal positif serta meng-abdi kepada lembaga tersebut.

Narapidana yang direkrut menjadi pustakawan di Perpustakaan Lembaga Pemasyaraka-tan 
Billy Ainul Ilham

Peranan Perpustakaan Dalam Meningkatkan Literasi Informasi

Perempuan Klas IIA Tangerang harus meme-nuhi kriteria yang ditentukan pihak Lembaga Pemasyarakatan (Lapas). Adapun kriteria narapida-na untuk menjadi pustakawan di Lembaga Pemasyarakatan Perempuan Klas IIA Tangerang di antaranya, pertama, narapidana minimal telah menempuh jenjang pendidikan Sekolah Menengah Atas karena dianggap telah dewasa dalam pola berpikir. Kedua, narapidana memiliki dedi-kasi, berkorban waktu dan pikiran untuk dapat bekerja di perpustakaan. Ketiga, narapidana me-miliki loyalitas, rasa tanggung jawab dan kese-tiaan. Keempat, narapidana dapat mengevaluasi sikap karena pihak Lembaga Pemasyarakatan (Lapas) akan mengevaluasi perilaku narapidana melalui riwayat hidupnya selama berada di Lembaga Pemasyarakatan (Lapas).

Setelah pihak Lembaga Pemasyarakatan (Lapas) merekrut pustakawan, lalu diadakan pe-mbinaan dan pelatihan kepustakawanan kepada narapidana calon pustakawan. Materi pembinaan dan pelatihan yang diberikan ialah bagaimana m-nyeleksi dan mengelola koleksi. Seorang narapi-dana yang menjadi pustakawan, akan mendapat-kan pengetahuan dan pengalaman yang baru. Selain itu, narapidana akan memperoleh remisi sebagai reward.

Lembaga Pemasyarakatan Perempuan Klas

IIA Tangerang didirikan untuk menambah wawa-san, pengetahuan serta pengalaman para narapi-dana. Perpustakaan tersebut dikelola pustaka-wan dan tamping (anggota narapidana yang di-percaya membantu pustakawan). Jadi, tamping Lembaga Pemasyarakatan (Lapas) dipercaya un-tuk mengelola perpustakaan dan nantinya akan mendapatkan pelatihan dalam pengelolaan per-pustakaan. Tamping Lembaga Pemasyarakatan (Lapas) mendapat pelatihan agar dapat menge-lola koleksi di perpustakaan dengan baik seperti perpustakaan pada umumnya. Hal tersebut dilakukan mengingat pustakawan Lembaga Pemas- yarakatan (Lapas) berasal dari pihak narapida-na, di mana narapidana tidak memiliki latar bela-kang keilmuan ilmu perpustakaan. Oleh ka-rena itu, mereka perlu mengikuti pembekalan menge-nai perpustakaan sebelum terjun mengelola per-pustakaan.

\section{KESIMPULAN}

Berdasarkan penjelasan yang telah dipaparkan, dapat disimpulkan bahwa Perpustakaan Lembaga Pemasyarakatan (Lapas) merupakan perpus-takaan khusus yang melayani pemustaka narapi-dana, yang pengelolaan perpustakaannya dike-lola oleh Kepala Sub Bidang Pengelola Pembi-naan Kepribadian dengan dibantu narapidana se-bagai pustakawan melalui kriteria tertentu. Man-ajemen perpustakaan dilakukan dengan mene-rapkan beberapa kaidah perpustakaan secara umum. Adapun peran Lembaga Pemasyarakatan Perempuan Klas IIA Tangerang dalam meningkatkan literasi informasi narapidana merupakan suatu kearifan lokal tersendiri. Perpustakaan Le-mbaga Pemasyarakatan (Lapas) menjadi wadah bagi para narapidana untuk mengembangkan lit-erasi informasinya. Narapidana sudah dapat dik-atakan mampu meningkatkan kemampuan lite-rasi informasi walaupun sumber informasi di per-pustakaan masih terbatas. Indikator yang dapat dilihat dari kegiatan literasi informasi di Lembaga Pemasyarakatan (LAPAS) ini adalah adanya hasil karya dari narapidana, yaitu berupa buku, karya seni lukisan, dan budidaya tanaman. Keberadaan perpustakaan menjadi sangat penting bagi nara-pidana, selain sebagai sumber informasi utama, perpustakaan juga menjadi salah satu pilihan bagi narapidana untuk menghilangkan rasa bo-san selama menjalani masa tahanan. Adapun ko-leksi yang disediakan yaitu berupa pengetahuan agama untuk menambah pengetahuan narapi-dana dalam beragama, koleksi pengetahuan um-um yang dapat memperkaya wawasan narapi-dana, serta koleksi yang bersifat menghibur nar-apidana seperti novel. 
Almaktabah Vol. 5, No. 1, Juni 2020

Kegiatan manajemen per-pustakaan masih dilakukan secara manual kare-na minimnya perhatian dari pihak Lembaga Pem-asyarakatan (Lapas) terhadap perpustakaan. Diharapkan penelitian ini dapat dijadikan acuan untuk penelitian selanjutnya tentang bagaimana memanajemen perpustakaan khusus yang baik agar kemampuan literasi informasi para nara-pidana meningkat.

\section{DAFTAR PUSTAKA}

Arikunto, S. (2013). Manajemen Penelitian. Jakarta: PT. Asdi Mahasatya.

Kamariah, T. 2013. kajian perpustakaan khusus dan sumber informasi di Indonesia.Jurnal dokumentasi dan informasi, 34 (1), 31.

Karina, O. 2019. Peran Perpustakaan Lem-baga Pemasyarakatan Klas I Malang dalam meningkatkan literasi informasi narapidana. Jurnal kajian informasi \& perpustakaan, 7(1), 53

Kayyis Ar, Muhammad.2020. Mengenal 10 Prinsip Pemasyarakatan dalam Kegiatan Pembinaan Narapidana. Dalam https://jarrak.id/catatanredaksi-mengenal-10-prinsip pemasyarakatan dalam-kegiatan-pembinaan-

narapidana,Diakses pada 17 januari 2020

Moleong, L.J. (2010). Metodologi Penelitian Kualitatif. Bandung: PT. Remaja Rosdakarya

Republik Indonesia. 1995. Undang-undang No. 12 Tahun 1995 tentang Pemasyarakatan

Republik Indonesia. 2007. Undang-undang No. 43 Tahun 2007 tentang Perpustakaan 